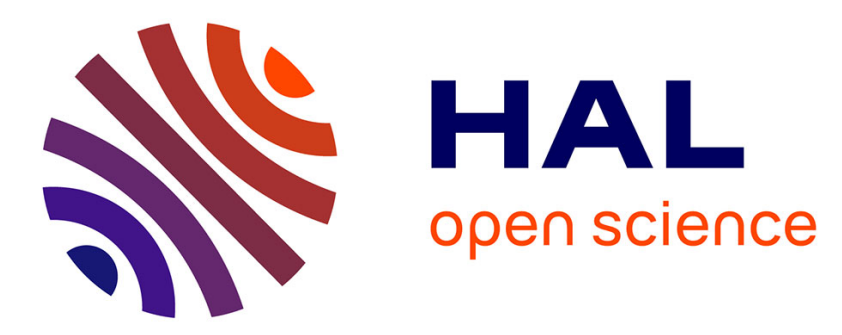

\title{
Conformational Transformations of Sulfur-Containing Rings: 2-Methyltetrahydrothiophene Gas-Phase Structures
}

\author{
Vinh Van, Christina Dindic, Ha Vinh Lam Nguyen, Wolfgang Stahl
}

\section{To cite this version:}

Vinh Van, Christina Dindic, Ha Vinh Lam Nguyen, Wolfgang Stahl. Conformational Transformations of Sulfur-Containing Rings: 2-Methyltetrahydrothiophene Gas-Phase Structures. ChemPhysChem, 2015, 16 (2), pp.291-294. 10.1002/cphc.201402727 . hal-03183159

\section{HAL Id: hal-03183159 \\ https://hal.science/hal-03183159}

Submitted on 12 Apr 2021

HAL is a multi-disciplinary open access archive for the deposit and dissemination of scientific research documents, whether they are published or not. The documents may come from teaching and research institutions in France or abroad, or from public or private research centers.
L'archive ouverte pluridisciplinaire HAL, est destinée au dépôt et à la diffusion de documents scientifiques de niveau recherche, publiés ou non, émanant des établissements d'enseignement et de recherche français ou étrangers, des laboratoires publics ou privés. 


\title{
Conformational Transformations of Sulfur-Containing Rings: 2- Methyltetrahydrothiophene Gas-Phase Structures
}

\author{
Vinh Van, ${ }^{[a]}$ Christina Dindic, ${ }^{[a]}$ Ha Vinh Lam Nguyen, ${ }^{*}{ }^{[a, b]}$ and Wolfgang Stahl[a]
}

\begin{abstract}
Stable conformations of five-member rings with the prototype cyclopentane are well-known to exist as twist or envelope structures and are of general interest in chemistry. Here, we report on the conformational analysis of the sulfur-containing ring 2methyltetrahydrothiophene studied by a combination of molecular beam Fourier transform microwave (MB-FTMW) spectroscopy and quantum chemistry. Two twist conformers were observed, whereby highly accurate molecular parameters could be determined. In addition, the ${ }^{34} \mathrm{~S}$-isotopologue of the most stable conformer was assigned in natural abundances. Geometry optimizations were performed at different levels of theory and the calculated rotational constants were compared with experimental values. Two transition states optimized at the MP2/6-311++G(d,p) level using the Berny algorithm could illustrate the intramolecular conversion between both conformers.
\end{abstract}

Volatile heterocyclic flavor substances are of interest to understand the aroma production during food cooking. For example, the Maillard reaction is known to create desirable aromas in browned food under heating. The educts of this reaction are amino acids and reducing compounds; the products are mixtures of flavor substances. In 1995, Umano et al. reported on the formation of odor compounds by heating $D$ glucose and L-cysteine as a Maillard model, where thiophenes are important sulfur-containing products [1]. Here, our studies on the gas phase conformations of 2-methyltetrahydrothiophene (MTTP), a product of the aforementioned Maillard reaction, will be reported. MTTP is also found as natural flavor in Petite Arvine wine [2] and Chinese brandy [3]. In 1984, Hartman et al. [4] identified this molecule in the volatile products after thermal degradation of vitamin $B_{1}$, which provides a better understanding of the nutrient loss progress.

Nowadays, quantum chemistry is a powerful help tool to assign rotational spectra. The optimized geometries often yield reasonable estimations to start the spectral assignment. Conversely, experimental parameters obtained by microwave spectroscopy can be used for benchmark calculations [5]. Under molecular beam conditions, we expect to observe several twist conformations of MTTP, which are linked by envelope transition states. The twist conformations often appear as the most stable

[a] Vinh Van, Christina Dindic, Prof. Dr. Wolfgang Stah Institute of Physical Chemistry, RWTH Aachen University, Landoltweg 2, D-52074 Aachen, Germany.

[b] Dr. Ha Vinh Lam Nguyen* Laboratoire Interuniversitaire des Systèmes Atmosphériques (LISA), UMR 7583 (CNRS/Univ. Paris Est \& Paris Diderot), Université de Paris Est, 61 avenue du Général de Gaulle, F-94010 Créteil cedex, France. E-mail: lam.nguyen@lisa.u-pec.fr

Supporting information for this article is given via a link at the end of the document. structures in many other five-membered rings [6-8].

MTTP is a five-membered heterocyclic molecule and possesses a stereo center. At the beginning, several starting geometries based on the structures of two conformers of the prototype cyclopentane [9] were created and optimized at the MP2/6-311++G(d,p) level using the GAUSSIAN package [10]. Harmonic frequency calculations were performed to verify the nature of the stationary points.

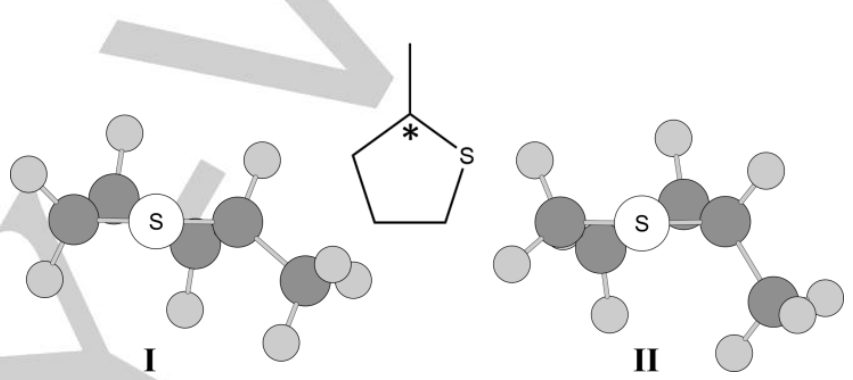

Figure 1. Conformer I and II calculated at the MP2/6-311++G(d,p) level as well as the structural formula of MTTP with its stereo center marked by star. The energy difference between conformer II and the more stable conformer I is $0.99 \mathrm{~kJ} \cdot \mathrm{mol}^{-1}$

Figure 1 indicates two twist conformers (I and II) obtained by quantum chemical calculations. In general, twist conformations can be described by the angle $\alpha$ between the $\mathrm{C}_{1}-\mathrm{S}-\mathrm{C}_{7}$ plane and $\mathrm{C}_{2}-\mathrm{C}_{14}$ vector as shown in Figure 2. They are additionally characterized by the angles $\beta$ and $\beta$ ' between the $\mathrm{C}_{1}-\mathrm{S}-\mathrm{C}_{7}$ plane and the twisted planes $\mathrm{C}_{2}-\mathrm{C}_{14}-\mathrm{C}_{7}$ and $\mathrm{C}_{1}-\mathrm{C}_{2}-\mathrm{C}_{14}$, respectively.
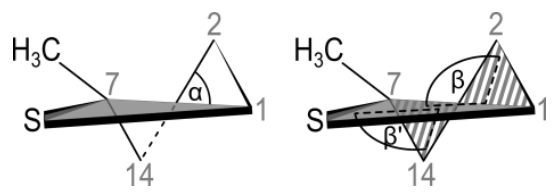

Figure 2. Definitions of the angles $\alpha, \beta$, and $\beta^{\prime}$ in the twisted conformation of MTTP.

$\beta$ and $\beta$ ' are equal if the ring plane described by the dihedral angle $\varphi=\angle\left(\mathrm{C}_{1}-\mathrm{C}_{2}-\mathrm{C}_{14}-\mathrm{C}_{7}\right)$ is not distorted. The structures of conformer I and II illustrated in Figure 1 were re-optimized at different levels of theory using various combinations with the HF, DFT, MP2, and CCSD methods and different basis sets. The Cartesian coordinates are given in Table $\mathrm{S}-1$; the rotational constants and dipole moment components in Table S-2 in the Supporting Information (SI).

Two transition states (TS1 and TS2) were optimized using the Berny algorithm [11] to understand the conversion between 
the stable conformers I and II. Contrary to our chemical intuition, optimized geometries of the transition states do not show a planar ring structure. Depending on the orientation of the methyl group, envelope conformations with more or less pronounced distortion were found and visualized in Figure 3. These transition states were subsequently re-optimized at different levels of theory. The intramolecular conversion is shown in Figure 4.

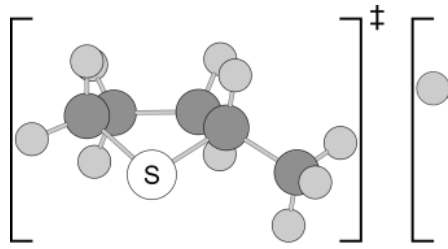

TS1

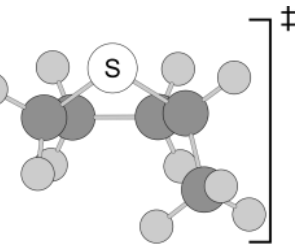

TS2
Figure 3. The transition states TS1 (methyl group in equatorial position) and TS2 (methyl group in axial position, $1.43 \mathrm{~kJ} \cdot \mathrm{mol}^{-1}$ higher in energy than TS1) with envelope structures where the sulfur atom indicates the envelop flap.

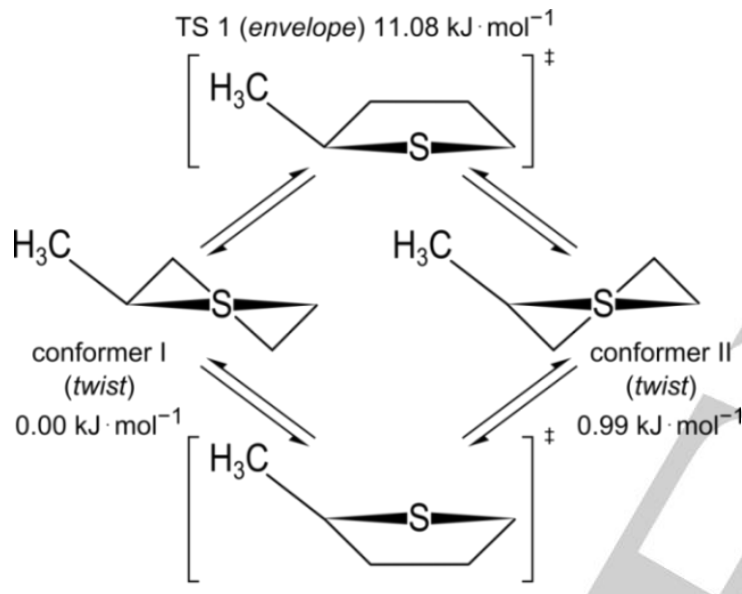

TS 2 (envelope) $12.51 \mathrm{~kJ} \cdot \mathrm{mol}^{-1}$

Figure 4. Intramolecular conversion between two stable twist conformers and the corresponding envelope transition states. The energies are related to the lowest energetic conformer I with its absolute energy $E=-593.6422076$ Hartree.

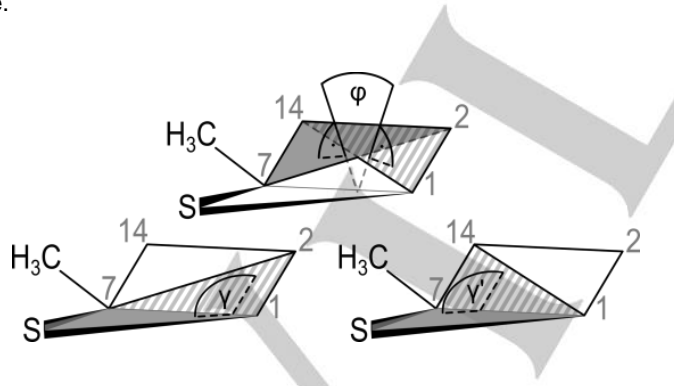

Figure 5. The envelope conformation is described by the dihedral angles $\varphi, \gamma$ and $\gamma^{\prime}$. If the ring structure is not distorted, $\varphi=0$ and $\gamma=\gamma^{\prime}$.

If the methyl group is in axial orientation, the ring plane (described by the dihedral angle $\varphi=\angle\left(\mathrm{C}_{1}-\mathrm{C}_{2}-\mathrm{C}_{14}-\mathrm{C}_{7}\right)$ ) is less distorted than in the case of equatorial orientation (for a planar ring structure, $\varphi=0$ ). Normally, the geometry of an envelope conformation can be described sufficiently by the position of the out-of-plane atom. Here, since the ring plane is distorted $(\varphi \neq 0)$, two dihedral angles $\gamma=\angle\left(\mathrm{S}-\mathrm{C}_{7}-\mathrm{C}_{1}-\mathrm{C}_{2}\right)$ and $\gamma^{\prime}=\angle\left(\mathrm{S}-\mathrm{C}_{7}-\mathrm{C}_{1}-\mathrm{C}_{14}\right)$ given in Figure 5 are additionally required to define the flap angle of the envelope. The rotational constants and angles $\varphi, \gamma$, and $\gamma^{\prime}$ of TS1 and TS2 are available in Table S-3 in the SI.

The transition state showing a planar ring structure was obtained while $\varphi$ and $\gamma^{\prime}$ were kept fixed to zero and all other parameters were allowed to relax. Harmonic frequency calculations yielded two imaginary frequencies. This second order transition state is $20.63 \mathrm{~kJ} \cdot \mathrm{mol}^{-1}$ higher in energy than the first order one TS1.

As illustrated in Figure 4, two stable conformers of MTTP have an energy difference of only $0.99 \mathrm{~kJ} \cdot \mathrm{mol}^{-1}$. Therefore, both are expected to be observed under our molecular beam conditions. At the beginning of the spectroscopic studies, a broadband scan was recorded in the frequency range from 9 to $14 \mathrm{GHz}$, where overlapped spectra were automatically taken by a step width of $0.25 \mathrm{MHz}$. Afterwards, all lines were remeasured in the high resolution mode of the spectrometer. They appeared as doublets due to the Doppler effect. Figure S-1 in the SI shows a typical spectrum in the high resolution mode.

The microwave spectrum was predicted with the program $X I A M$ [12] using the rotational constants calculated at the MP2/6-311++G(d,p) level. The dipole moment components suggested a spectrum with much stronger $b$-type transitions for both conformers (see Table S-2a). We started our assignment for conformer I with the transitions $2_{12} \leftarrow 1_{01}, 3_{03} \leftarrow 2_{12}$, and $3_{13}$ $\leftarrow 2_{02}$. By trial and error, these transitions could be assigned and they were the most intensive transitions in the scan. Afterwards, more $b$-type transitions were found and added to the fit. We also tried to assign a-type transitions, since the dipole moment component in a-direction was calculated to be small but not zero. Surprisingly, all measured a-type transitions were much stronger than expected. The calculated $c$-dipole moment component was zero and accordingly, no $c$-type transitions could be observed. In total, 42 a-type and $101 \mathrm{~b}$-type transitions were fitted to a standard deviation of $1.7 \mathrm{kHz}$, within the experimental accuracy of $2 \mathrm{kHz}$. All fitted transitions are listed in Table S-4a in the $\mathrm{SI}$, the molecular parameters in Table 1.

Table 1. Molecular parameters of conformer I, conformer II, and the ${ }^{34} \mathrm{~S}$ isotopologue of conformer I obtained using the program XIAM.

\begin{tabular}{cllll}
\hline$[\mathrm{a}]$ & Unit & ${ }^{32}$ S-conformer I & ${ }^{34}$ S-conformer I & ${ }^{32}$ S-conformer II \\
\hline$A$ & $\mathrm{GHz}$ & $4.225235990(81)$ & $4.12369534(16)$ & $3.789899843(97)$ \\
$B$ & $\mathrm{GHz}$ & $2.790053737(51)$ & $2.78965253(12)$ & $3.008622018(74)$ \\
$C$ & $\mathrm{GHz}$ & $1.848361318(52)$ & $1.82856748(11)$ & $2.031137229(73)$ \\
$\Delta_{J}$ & $\mathrm{kHz}$ & $0.25971(53)$ & $0.2615(21)$ & $0.5337(20)$ \\
$\Delta_{J}$ & $\mathrm{kHz}$ & $0.1197(13)$ & $0.1220(28)$ & $-0.7783(13)$ \\
$\Delta_{K}$ & $\mathrm{kHz}$ & $1.1338(12)$ & $1.0727(30)$ & $1.8994(16)$ \\
$\delta_{J}$ & $\mathrm{kHz}$ & $0.06270(21)$ & $0.06217(54)$ & $0.08759(20)$ \\
$\delta K$ & $\mathrm{kHz}$ & $0.31438(82)$ & $0.3155(23)$ & $0.23542(67)$ \\
$\sigma^{[\mathrm{b}]}$ & $\mathrm{kHz}$ & 1.7 & 1.8 & 1.1 \\
$\mathrm{~N}^{[\mathrm{c}]}$ & & 143 & 75 & 77 \\
\hline
\end{tabular}

[a] All parameters refer to the principal axis system. Watson's A reduction in $\mathrm{I}^{\mathrm{r}}$ representation was used. [b] Standard deviation of the fit. [c] Number of lines. 
Quantum chemically, conformer I should be the most stable one, which is confirmed by the experiment, since all transitions assigned to conformer I are quite strong. From our experience, the rotational spectrum of the ${ }^{34} \mathrm{~S}$-isotopologue of the most stable conformer can be observed in its natural abundances of about $4.3 \%$. The assignment process followed the steps carried out for conformer I. In total, $75 a$ - and $b$-type transitions of the ${ }^{34} \mathrm{~S}$-isotopologue were assigned. The frequency list is given in Table S-4b, the molecular parameters also in Table 1. The $A$ and $B$ rotational constants are almost the same as those of the main isotopologue; the $C$ constant is appreciably lower.

After conformer $\mathrm{I}$ and its ${ }^{34} \mathrm{~S}$-isotopologue were assigned, many lines remained in the scan, which might belong to conformer II. The assignment was started with the same $b$-type transitions $2_{12} \leftarrow 1_{01}, 3_{03} \leftarrow 2_{12}$, and $3_{13} \leftarrow 2_{02}$, which could be easily identified. For conformer II, $9 a$ - and $68 b$-type transitions were assigned and fitted to an excellent standard deviation of $1.1 \mathrm{kHz}$. The transition frequencies are listed in Table S-4c in the SI, the fitted parameter also in Table 1.

No complete structural determination can be carried out with only one ${ }^{34} \mathrm{~S}$ isotopic species. It is however possible to calculate the $r_{s}$ position of the sulfur atom with respect to the center of mass (isotopic shift). Using Kraitchman's equations [13], the ${ }^{32} \mathrm{~S}$ coordinates were found to be $|a|=0.101(15) \AA$, $|b|=1.2511(12) \AA,|c|=0.056(27) \AA$. The errors are estimated with Costain's method [14]. The position of the sulfur atom is in excellent agreement with the calculated results of $a=0.1003 \AA$, $b=-1.2282 \AA, c=-0.0589 \AA$ (see Table S-1).

The experimental rotational constants were compared with those from quantum chemical calculations. Best agreements could be found at the CCSD/cc-pVTZ level for both conformers I and II, as shown in Table S-2a and S-2b. For conformer I, the HF method in combination with various basis sets provided rotational constants with better agreement than calculations using the MP2 and B3LYP methods, which is very probably due to error compensation. Conversely, the MP2 method yielded better agreement for conformer II.

The methyl group in MTTP undergoes internal rotation and causes A-E splittings of all rotational lines [15]. The barrier heights are calculated to be $1349 \mathrm{~cm}^{-1}$ and $1268 \mathrm{~cm}^{-1}$ for conformer I and II, respectively, which are rather high. Accordingly, A-E splittings are only observable for a few transitions. An example is illustrated in Figure S-2 in the SI. Since these splitting are very small, the effect of internal rotation was not taken into account.

To summarize, conformational analysis of MTTP with quantum chemical calculations yielded two stable twist conformers (I and II) and two envelope transition states. The microwave spectra of both conformers as well as the ${ }^{34} \mathrm{~S}$ isotopologue of conformer I were assigned. Molecular parameters like the rotational, centrifugal distortion constants, and the position of the sulfur atom in respect to the center of mass of conformer I could be determined with very high accuracy. The observed spectra were reproduced within our experimental accuracy of $2 \mathrm{kHz}$. This study confirms that the twist and envelope structures of stable conformers and transition states, respectively, are energetically favorable as also found in some related five-member rings.

\section{Experimental Section}

The rotational spectra were measured with a MB-FTMW spectrometer operating in the frequency range from 2 to $26.5 \mathrm{GHz}$. Details of the spectrometer were described elsewhere $[16,17]$ and will not be repeated here. MTTP was purchased from TCl Deutschland GmbH, Eschborn, Germany with a stated purity of over $98 \%$ and used without further purification. For the measurements, a $5 \mathrm{~cm}$-long piece of a pipe cleaner was soaked into the liquid substance and placed directly in front of the nozzle. Helium at a pressure of approximately $200 \mathrm{kPa}$ was allowed to flow over the sample. The helium-substance mixture was expanded through the pulsed nozzle into the cavity.

\section{Acknowledgements}

The authors thank the Land Nordrhein-Westfalen, the „Start-up” project and the undergraduate fond of the RWTH Aachen University, as well as the Université de Paris Est Créteil for funds. V. V. thanks the Fond der Chemischen Industrie (VCI) for a Ph.D. fellowship. Free computer time provided by the IT Center of the RWTH Aachen University is gratefully acknowledged.

Keywords: microwave spectroscopy • ab initio calculation • thiophene $\cdot$ conformation analysis $\cdot$ configuration determination

[1] K. Umano, Y. Hagi , K. Nakahara, A. Shyoji, T. Shibamoto, J. Agric. Food Chem. 1995, 43, 2212-2218.

[2] C. Fretz, S. Känel, J.-L. Luisier, R. Amadò, Eur Food Res Technol 2005, 221, 504-510.

[3] Y. P. Zhao, J. M. Li, B. C. Zhang, Y. Yu, C. H. Shen, P. Song, Jnl Institute Brewing 2012, 118, 315-324.

[4] G. J. Hartman, J. T. Carlin, J. D. Scheide, C.-T. Ho, J. Agrlc. Food Chem. 1984, 32, 1015-1018.

[5] S. Grimme, M. Steinmetz, Phys. Chem. Chem. Phys. 2013, 15, 16031 16042.

[6] J. L. Alonso, J. C. López, R. M. Villamañán, J. Mol. Spectrosc. 1987, 126, 348-355

[7] a) A. K. Mamleev, N. M. J. Pozdeev, Struct. Chem. 1969, 10, 643-644; b) L. Margulès, M E. Sanz, S. Kassi, D. Petitprez, G. Wlodarczak, J. C. López, J. E. Boggs, Chem. Phys. 2001, 263, 19-31.

[8] H. Mouhib, V. Van, W. Stahl, J. Phys. Chem. A 2013, 117, 6652-6656.

[9] D. A. Lightner, J. E. Gurst, Organic Conformational Analysis and Stereochemistry from Circular Dichroism Spectroscopy, J. Wiley-VCH, New York, 2000

[10] M. J. Frisch et al., Gaussian 09, Revision A.02, Gaussian, Inc. Wallingford CT, 2009.

[11] H. B. Schlegel, J. Comput. Chem. 1982, 3, 214-218.

[12] H. Hartwig, H. Dreizler, Z. Naturforsch. 1996, 51a, 923-932.

[13] J. Kraitchman, Amer. J. Phys. 1953, 21, 17-24.

[14] C. C. Costain, Trans. Am. Crystallorg. Asscoc.1966, 2, 157-164.

[15] H. Dreizler, Z. Naturforsch. 1961, 16a, 1354-1367.

[16] U. Andresen, H. Dreizler, J.-U. Grabow, W. Stahl, Rev. Sci. Instrum. 1990, 61, 3694-3699.

[17] J.-U. Grabow, W. Stahl, H. Dreizler, Rev. Sci. Instrum. 1996, 67, 4072 4084. 


\section{Entry for the Table of Contents}

\section{COMMUNICATION}

Are the twist or the envelope structures the most stable conformations of five-membered heterocyclic molecules, and how are they linked by transition states? Our studies using a combination of molecular beam Fourier transform microwave spectroscopy and quantum chemistry give an answer for a particular tetrahydrothiophene derivative.

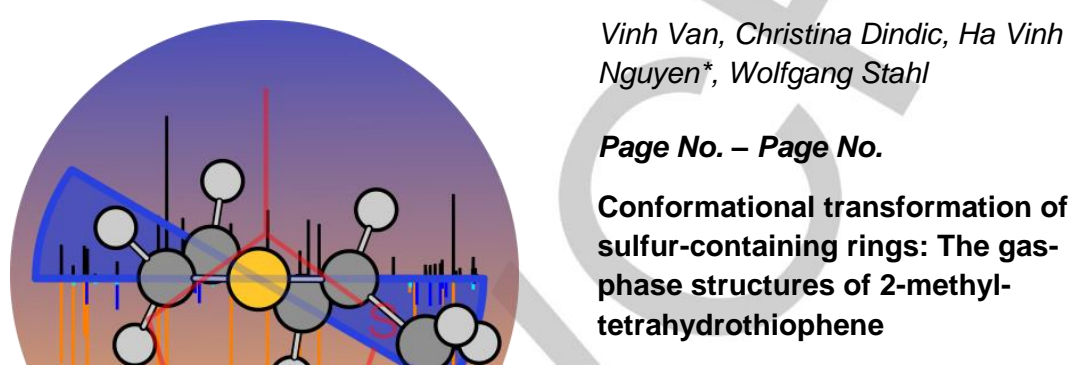

Vinh Van, Christina Dindic, Ha Vinh Lam tetrahydrothiophene 